\title{
Short-Term Results of Combined Open Reduction and Internal Fixation in the Treatment of Trans-Scaphoid Perilunate Fracture- Dislocation
}

\author{
(D) Erdinç Acar, (1) Uğur Bezirgan
}

Clinic of Orthopaedics and Traumatology, Ankara City Hospital, Division of Hand and Upper Extremity Surgery, Ankara, Turkey

\begin{abstract}
Aim: This study aimed to evaluate the short-term clinical and radiographic results of combined open reduction and internal fixation in the treatment of trans-scaphoid perilunate fracture-dislocation (TSPLFD).

Materials and Methods: Data of eight patients diagnosed with TSPLFD who underwent combined open reduction and internal fixation and followed for a minimum of 8 months were retrospectively analyzed. All patients underwent surgical treatment with an Acutrak ${ }^{\circledR}$ screw, ligament repair using suture anchors, and Kirschner wire. The functional outcomes were evaluated using the modified Mayo Wrist Scores and total active range of motion scale. Radiographic outcomes were assessed based on standard X-ray images of the wrist.

Results: Of the patients, seven were male and one was female, and the median age was 32 years (range: 20-44). The median follow-up duration was 12 months (range: 8-16). According to the TAROM scores, the outcomes were excellent and good in one and seven patients, respectively. The median Mayo Wrist Scores were 84 (range: 80-95). Good radiographic results were achieved in all patients. No surgery-related complications such as infection, loss of reduction, and Sudeck's atrophy were observed.
\end{abstract}

Conclusion: Although TSPLFD is a rare condition, early diagnosis and surgical treatment yield favorable functional and radiographic results. However, post-traumatic arthritis and functional dissatisfaction may occur in the long term.

Keywords: Trans-scaphoid perilunate fracture-dislocation, dorsal approach, Acutrak screw, suture anchor, Kirschner wire

\section{Introduction}

Trans-scaphoid perilunate fracture-dislocation (TSPLFD) is an uncommon injury of the wrist, usually caused by high-energy trauma $(1,2)$. It is more frequent in adult males and up to $25 \%$ of cases are missed in the initial presentation $(3,4)$. Dorsal perilunate fracture-dislocation is the most common type of TSPLFD characterized by the dorsal dislocation of the capitate head from the distal lunate joint $(3,5)$. Treatment options of TSPLFD include closed reduction, open reduction with a dorsal approach, volar approach, or combined (dorsal + volar) approach, and arthroscopy-assisted reduction (6-9).
In the present study, we aimed to evaluate short-term clinical and radiographic results of combined open reduction and internal fixation in the treatment of TSPLFD.

\section{Materials and Methods}

This single-center, retrospective study was conducted between January 2019 and July 2020. A total of eight patients who were admitted to the emergency unit with high-energy injuries and underwent combined open reduction and internal fixation with the diagnosis of TSPLFD and who were followed for minimum eight months were included. The study period encompassed the entire duration of surgery, follow-up, and data collection and 
analysis. All patients were surgically treated with an Acutrak ${ }^{\circledR}$ screw, ligament repair using suture anchors, and Kirschner wire (K-wire). A written informed consent was obtained from each patient for all diagnostic and therapeutic procedures. The study protocol was approved by the Local Ethics Committee of Ankara City Hospital (no: E1-20-1230, date: 28.10.2020). The study was conducted in accordance with the principles of the Declaration of Helsinki.

All patients underwent a detailed medical history interview, physical, local, and systemic examinations. Bilateral wrist radiographs were obtained (Figures 1 and 2) and computed tomography was performed. Based on the results, surgery was decided. All operations were carried out by two hand surgeons under general anesthesia. A 4-cm longitudinal skin incision ulnar to the Lister's tubercle was made. The extensor pollicis longus tendon was released distally and retrieved from the third extensor compartment. The joint capsule was reached through the second and fourth compartments. The capsule was opened using a T-shaped incision. The K-wires were placed into

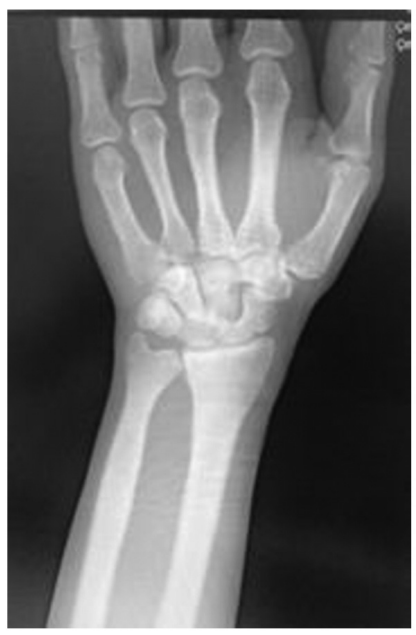

Figure 1. Anteroposterior X-ray of trans-scaphoid perilunate fracture-dislocation

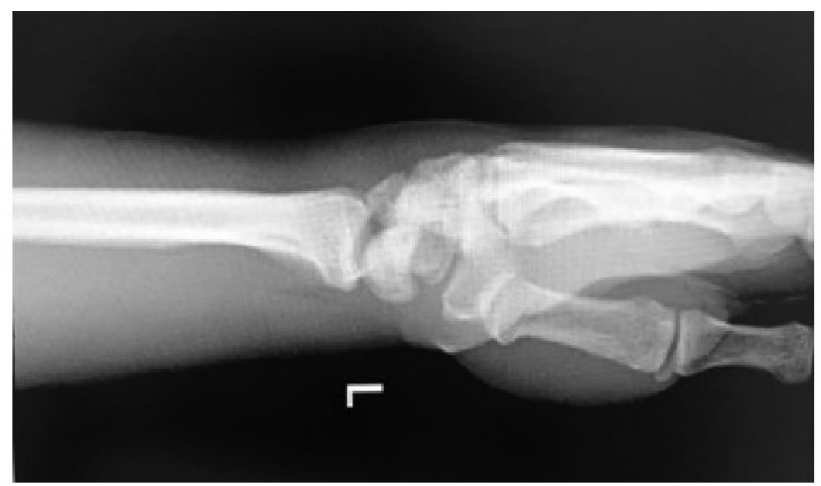

Figure 2. Lateral X-ray of trans-scaphoid perilunate fracturedislocation the scaphoid fracture line and used as joysticks for reduction. Then, two thin K-wires were placed dorsally to fix the scaphoid. Following drilling of the most central K-wire under the guidance of fluoroscopy, compression was applied using an Acutrak ${ }^{\circledR}$ (Acumed Inc., OR, USA) screw. The dorsal lunotriquetral ligament was ruptured with joint instability. The ligament was reduced using surgical instruments and the lunotriquetral joint was stabilized via two percutaneous K-wires through the triquetrum. A mini-anchor $(2.0 \mathrm{~mm})$ was threaded on the lunate and the lunotriquetral ligament was repaired with reinforced suture anchors. The joint capsule was repaired via 3-0 polydioxanone (PDS) suture (Ethicon Inc., NY, USA) and the extensor retinaculum was approximated via 4-0 PDS suture. The skin was closed with 4-0 prolene sutures.

Following the wound dressing, the wrist through the volar capsule was casted in neutral alignment using short-arm casts. The absence of postoperative neurovascular deficit was confirmed, and control X-ray was performed (Figures 3 and 4). Wound dressing was advised to the patients and/or their caregivers every three days. The patients were scheduled for

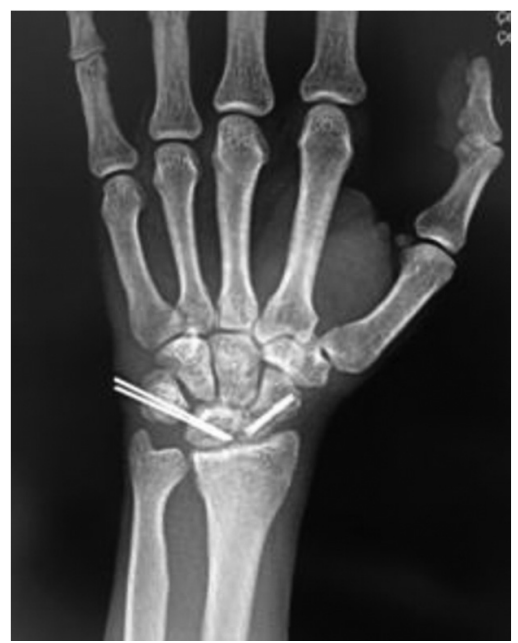

Figure 3. Postoperative anteroposterior X-ray of a 32-year-old male patient

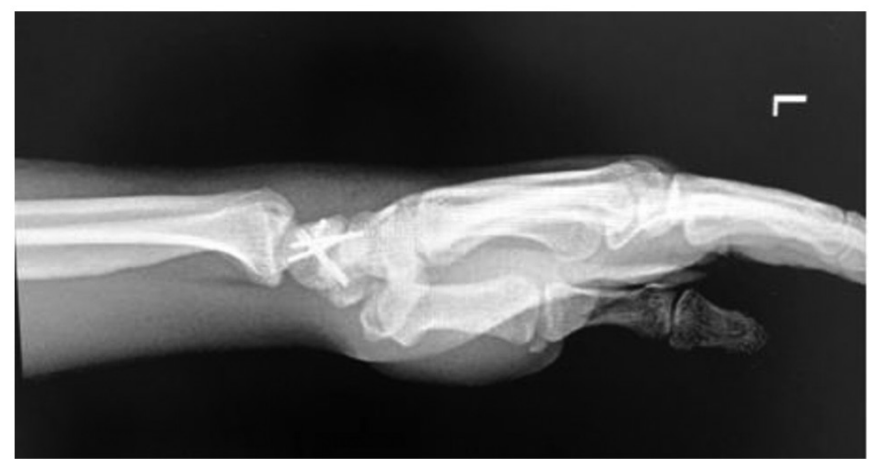

Figure 4. Postoperative lateral X-ray of a 32-year-old male patient 
follow-up on postoperative day $7^{\text {th }}$ and the absence of loss of reduction was confirmed by radiographs. The sutures were removed at week $2^{\text {nd }}$ and a circular short-arm plaster cast was placed. At week $6^{\text {th }}$, the K-wires were retrieved from all patients under local anesthesia. The patients and/or caregivers were instructed to do wrist exercises at home and were referred to the hand rehabilitation unit. The rehabilitation program was applied both under the supervision of physiotherapists and as a self-supervised program. At three months following surgery, the range of motion (ROM) measurements were performed. The patients in whom the ROM was normal were scheduled for follow-up at $6^{\text {th }}$ and $12^{\text {th }}$ months (Figures 5 and 6 ).

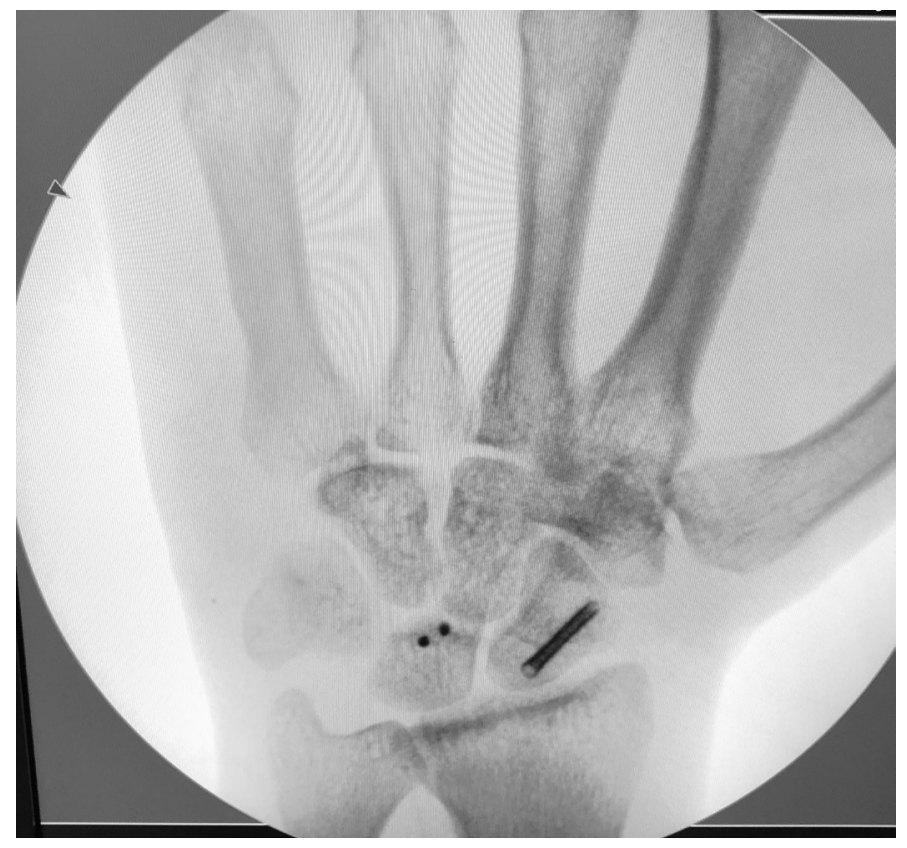

Figure 5. Postoperative anteroposterior X-ray of a 32-year-old male patient at one-year follow-up

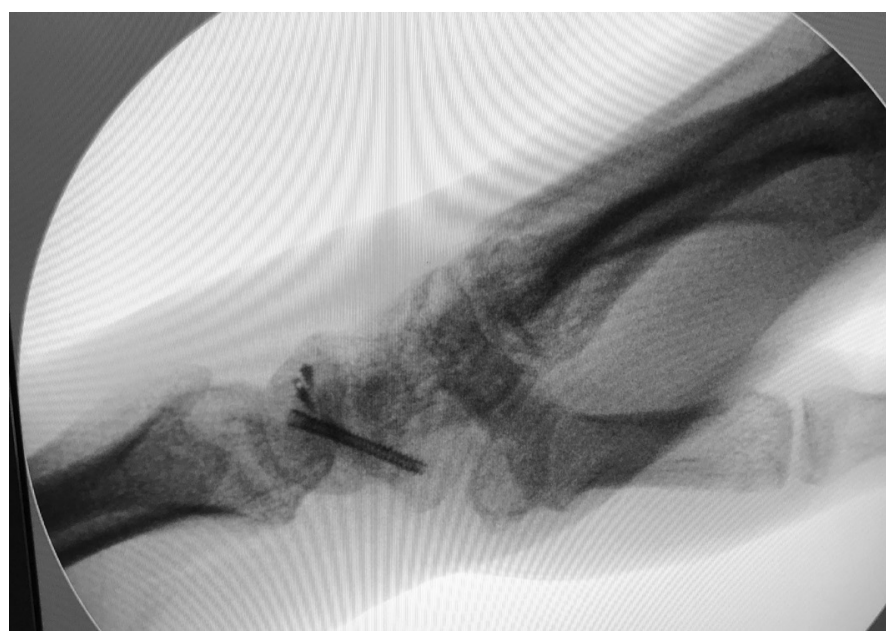

Figure 6. Postoperative lateral X-ray of a 32-year-old male patient at one-year follow-up
The functional outcomes were evaluated using the modified Mayo wrist scores and total active range of motion (TAROM) scale as excellent (90-100), good (80-90), fair (65-80), and poor $(<65)$. Flexion and extension were measured and the discrepancy between the operated and non-operated wrists was examined. Radiographic outcomes were assessed based on standard X-ray images of the wrist and were classified using the Herzberg classification (Table 1, Table 2) $(3,10)$.

\section{Statistical Analysis}

Statistical analysis was performed using the SPSS for Windows version 17.0 (SPSS Inc., Chicago, IL, USA). Descriptive data were expressed in median (minimum-maximum) or number and frequency, where applicable. The Student t-test was used to compare the ROM of the joint between the operated and nonoperated wrists. A p-value of $<0.05$ was considered statistically significant.

\section{Results}

Of the patients, seven were males and one was female with a median age of 32 (range: 20 to 44) years. The etiology of TSPLFD was a high-energy injury, including fall from a height in six patients, motorcycle accident in one patient, and in-vehicle accident in one patient. The patient with a history of fall from a height had an additional intra-articular distal tibial fracture

Table 1. Radiological and functional outcomes of the patients

\begin{tabular}{|l|l|}
\hline & Herzberg's classification \\
\hline Stage I & Lunate remained in place under the radius \\
\hline Stage Ila & $\begin{array}{l}\text { Lunate was palmarly dislocated but rotated by } \\
\text { less than } 900\end{array}$ \\
\hline Stage IIb & $\begin{array}{l}\text { Lunate was palmarly dislocated and rotated } \\
\text { more less than } 900\end{array}$ \\
\hline
\end{tabular}

\section{Table 2. Herzberg's radiological score}

\begin{tabular}{|l|l|}
\hline A & $\begin{array}{l}\text { Normal carpal alignment and morphology of carpal } \\
\text { bones }\end{array}$ \\
\hline & $\begin{array}{l}\text { Abnormal carpal alignment or morphology of carpal } \\
\text { bones; } 1 \text { or more of the following: } \\
\text { Static scapholunate dissociation } \\
\text { Static lunotriquetral dissociation } \\
\text { Ulnar translation of the carpus } \\
\text { Nonunion of scaphoid or other carpal bone } \\
\text { Balunion of scaphoid or other carpal bone (more } \\
\text { than 1 mm step-off on articular surfaces) } \\
\text { Collapse of lunate and or proximal pole of scaphoid, } \\
\text { suggesting avascularity } \\
\text { Carpal collapse pattern (dorsal intercalated segment } \\
\text { instability or volar intercalated segment instability) } \\
\text { without 1 of the above causes }\end{array}$ \\
\hline C & $\begin{array}{l}\text { X-ray film modified by the treatment (proximal row } \\
\text { carpectomy, wrist arthrodesis, etc.) }\end{array}$ \\
\hline
\end{tabular}


of the contralateral limb. At the time of admission, physical examination findings of the patients included tenderness over the radiocarpal joint and fovea radialis of the scaphoid bone with limited flexion, extension, supination, and pronation of the wrist. Posteroanterior X-ray revealed the interrupted lines of the Gilula (Figure 7), while lateral X-ray showed malalignment in the radius lunate and capitatum (Figure 8 ) (11). All patients, except

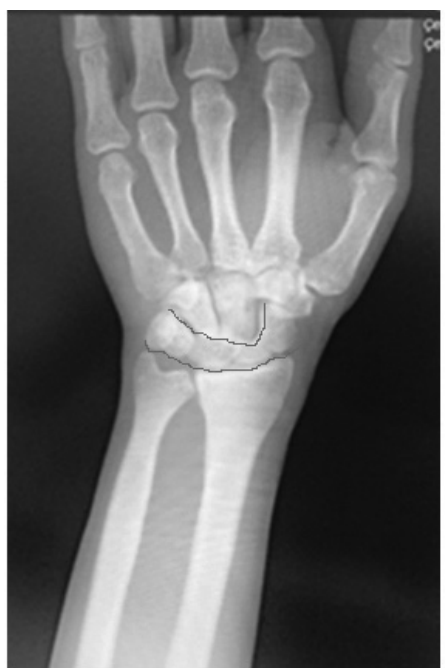

Figure 7. Irregular the interrupted lines of the Gilula

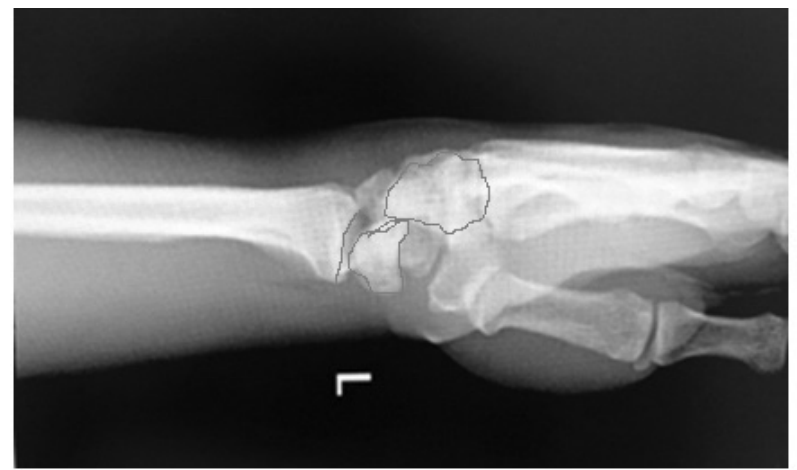

Figure 8. Malalignment in the radius, lunate and capitatum for one, underwent closed reduction in the emergency room. Following reduction, no neurological deficit was observed. The median time from the onset of injury to surgery was 1.5 days (range: 1 to 3), depending on the wrist edema. No postoperative neurovascular deficit was observed in any of the patients. The median time to discharge was 1.5 days (range: 1 to 3 ). The median follow-up was 12 months (range: 8 to 16).

The median time to K-wire removal was 6 weeks (range: 5 to 7). According to the TAROM scores, the results were excellent in one patient and good in seven patients. The median Mayo Wrist scores was 84 (range: 80 to 95). Good radiographic results were achieved in all patients. The median flexion was $50^{\circ}$ (range: $30^{\circ}$ to $85^{\circ}$ ) in the operated side and $70^{\circ}$ (range: $35^{\circ}$ to $90^{\circ}$ ) in the non-operated side $(p<0.05)$. The median extension was $30^{\circ}$ (range: $20^{\circ}$ to $60^{\circ}$ ) in the operated side and $50^{\circ}$ (range: $25^{\circ}$ to $65^{\circ}$ ) in the non-operated side $(p<0.05)$. According to Herzberg's classification, seven of the patients had Stage I and one had Stage IIb disease. No surgeryrelated complications such as infection, loss of reduction, or Sudeck's atrophy were observed during follow-up.

Radiological and functional outcomes of the patients are given in Table 3.

\section{Discussion}

Perilunate fracture-dislocations account for $2 \%$ to $3 \%$ of all carpal injuries (12). It is rarely reported in children (13), and frequently affects young male adults with an average age of 30 years (14). The most common causes are motorcycle accidents and fall from a height. Consistent with the literature, seven patients were male adults with a median age of 32 years (range: 20 to 44) in our study. The etiology of TSPLFD was a high-energy injury, including fall from a height in six patients, motorcycle accident in one patient, and in-vehicle accident in one patient. In addition, the patient with a history of fall from a height had an additional intra-articular distal tibial fracture of the contralateral limb.

\begin{tabular}{|c|c|c|c|c|c|}
\hline Case & Age/Sex & Follow-up (m) & Quality of reduction & Mayo wrist score & $\begin{array}{l}\text { Radiological herzberg } \\
\text { score }\end{array}$ \\
\hline 1 & $44 / \mathrm{M}$ & 8 & Good & 80 & A \\
\hline 2 & $41 / \mathrm{M}$ & 10 & Good & 82 & A \\
\hline 3 & $35 / M$ & 10 & Good & 82 & A \\
\hline 4 & $32 / \mathrm{M}$ & 12 & Good & 84 & A \\
\hline 5 & $32 / F$ & 12 & Poor & 84 & A \\
\hline 6 & $30 / \mathrm{M}$ & 14 & Good & 86 & A \\
\hline 7 & $25 / \mathrm{M}$ & 15 & Good & 86 & A \\
\hline 8 & $20 / M$ & 16 & Good & 95 & A \\
\hline
\end{tabular}


Perilunate fracture-dislocations are primarily evaluated based on the locations of the capitate and lunate. If the capitate is located in the dorsal lunate, it is classified as dorsal dislocation and if it is located in the volar lunate, it is classified as volar dislocation. The incidence of dorsal dislocations is higher than the volar type and, in the majority of cases, scaphoid fractures are accompanied, known as TSPLFD (14). In our study, all patients had dorsal dislocations presenting with scaphoid fractures.

Review of the literature reveals that time from injury to surgery and open fractures are the main prognostic factors of dorsal perilunate fracture-dislocations (15). In a study, Komurcu et al. (16) reported that early treatment of TSPLFD with open reduction and internal fixation yielded favorable results. In our study, the median time from the onset of injury to surgery was 1.5 days (range: 1 to 3), depending on the wrist edema. Of note, all of our patients had closed injuries.

Although rare, surgical treatment of acute perilunate dislocations with proximal row carpectomy and three-corner fusion has been described in the literature $(17,18)$. However, open reduction combined with a volar, dorsal or combined (dorsal + volar) approach is more frequently used in the daily practice $(19,20)$. The K-wire with and/without headless cannulated screws is widely applied to those presenting with additional scaphoid fractures. In the present study, all patients were treated through a dorsal approach and a headless cannulated screw was used for the treatment of scaphoid fractures. Ligament repair was performed using suture anchors and K-wire. These wires were buried beneath the skin and left in situ for about six weeks. In a previous study, the lunotriquetral ligament was repaired using the K-wire which was left in situ for minimum eight weeks (21).

Furthermore, there are several studies reporting median and ulnar nerve injuries following perilunate fracture-dislocations $(22,23)$. In our study, one patient had numbness in the first three fingers after surgery which resolved spontaneously at the end of six weeks. Neuropraxia was suspected in this patient and no additional treatment was given.

\section{Study Limitations}

The single-center, retrospective nature of the study with relatively small sample and short follow-up size are the main limitations of this study.

\section{Conclusion}

In conclusion, although TSPLFDs are rare entities, early diagnosis and surgical treatment yield favorable functional and radiographic results. However, post-traumatic arthritis and functional dissatisfaction may occur in the long-term.

\section{Ethics}

Ethics Committee Approval: The study protocol was approved by the Local Ethics Committee of Ankara City Hospital (no: E1-201230, date: 28.10.2020).

Informed Consent: A written informed consent was obtained from each patient for all diagnostic and therapeutic procedures.

Peer-review: Externally peer-reviewed.

\section{Authorship Contributions}

Surgical and Medical Practice: E.A., U.B., Concept: E.A., Design: E.A., Data Collection and Processing: E.A., Analysis of Interpretation: E.A, U.B., Literature Search: E.A., Writing: E.A.

Conflict of Interest: The authors declare that they have no conflict of interest.

Financial Disclosure: The authors declared that this study received no financial support.

\section{References}

1. Rockwood CA, Jr, Green DP, Bucholz RW. Fractures and dislocations of the wrist, in Rockwood CA, Jr, Green DP (eds): Fractures in Adults, Vol 1.NewYork: Lippincott Williams\&Wilkins Publishers; 201. p. 857-908.

2. Najarian R, Nourbakhsh A, Capo J, Tan V. Perilunate injuries. Hand (NY) 2011;6:1-7.

3. Herzberg G, Comtet JJ, Linscheid RL, Amadio PC, Cooney WP, Stalder J. Perilunate dislocations and fracture-dislocations: a multicenter study. J Hand Surg Am. 1993;18:768-79.

4. Grabow RJ, Catalano L 3 Carpal dislocations. Hand Clin. 2006;22:485-500.

5. Wingelaar M, Newbury P, Adams NS, Livingston AJ. Lunate Dislocation and Basic Wrist Kinematics. Eplasty. 2016;16:ic37.

6. Bagheri F, Taraz-Jamshidi MH, Birjandinejad A, Sharifi-Daloei SR, Mirkazemi M, Choghadeh MF, et al. Trans-scaphoid perilunate fracture-dislocation and isolated perilunate dislocations; surgical versus non surgical treatment. Arch Bone Jt Surg. 2013;1:74-7.

7. Murakawa D, Makino T, Kishimoto S, Hamamoto $\mathrm{H}$. Volar perilunate transscaphoid dislocation: a case. Hand Surg. 2014;19:419-21.

8. Meszaros T, Vögelin E, Mathys L, Leclère FM. Perilunate fracture-dislocations: clinical and radiological results of 21 cases. Arch Orthop Trauma Surg. 2018;138:287-97.

9. Jeon IH, Kim HJ, Min WK, Cho HS, Kim PT. Arthroscopically assisted percutaneous fixation for trans-scaphoid perilunate fracture dislocation. J Hand Surg Eur Vol. 2010;35:664-8.

10. Forli A, Courvoisier A, Wimsey S, Corcella D, Moutet F. Perilunate dislocations and transscaphoid perilunate fracture-dislocations: a retrospective study with minimum ten-year follow-up. J Hand Surg Am. 2010;35:62-8.

11. Sochart DH, Birdsall PD, Paul AS. Perilunate fracture-dislocation: a continually missed injury. J Accid Emerg Med. 1996;13:213-6.

12. Ada S, Özerkan F, Bora A, Ademoğlu Y, Kaplan İ. Perilunat kırıklı-çıkıkların cerrahi tedavi sonuçları. Acta Orthop Traumatol Turc. 1995;29:263-7.

13. Massicot R, Uzel AP, Céolin JL, Brouard P. Dorsal trans-scaphoid perilunate dislocation in a 9-year-old child. Eur J Pediatr Surg. 2005;15:140-3.

14. Hildebrand KA, Ross DC, Patterson SD, Roth JH, MacDermid JC, King GJ. Dorsal perilunate dislocations and fracture-dislocations: questionnaire, clinical, and radiographic evaluation. J Hand Surg Am. 2000;25:1069-79. 
15. Kara A, Celik H, Seker A, Kilinc E, Camur S, Uzun M. Surgical treatment of dorsal perilunate fracture-dislocations and prognostic factors. Int J Surg. 2015;24:57-63.

16. Komurcu M, Kürklü M, Ozturan KE, Mahirogullari M, Basbozkurt M. Early and delayed treatment of dorsal transscaphoid perilunate fracture-dislocations. J Orthop Trauma. 2008;22:535-40.

17. Muller T, Hidalgo Diaz JJ, Pire E, Prunières G, Facca S, Liverneaux P. Treatment of acute perilunate dislocations: ORIF versus proximal row carpectomy. Orthop Traumatol Surg Res. 2017;103:95-9.

18. Matthewson G, Larrivee S, Clark T. Case Report of an Acute Complex Perilunate Fracture Dislocation Treated with a Three-Corner Fusion. Case Rep Orthop. 2018;2018:8397638.

19. Sotereanos DG, Mitsionis GJ, Giannakopoulos PN, Tomaino MM, Herndon $\mathrm{JH}$. Perilunate dislocation and fracture dislocation: a critical analysis of the volar-dorsal approach. J Hand Surg Am. 1997;22:49-56.
20. Trumble T, Verheyden J. Treatment of isolated perilunate and lunate dislocations with combined dorsal and volar approach and intraosseous cerclage wire. J Hand Surg Am. 2004;29:412-7.

21. Laporte M, Michot A, Choughri H, Abi-Chahla ML, Pelissier P. Luxations et fractures-luxations périlunaires du carpe, étude rétrospective d'une série de 17 cas [Perilunate dislocations and fracture-dislocations of the wrist, a review of 17 cases]. Chir Main. 2012;31:62-70.

22. Mühldorfer-Fodor M, Hohendorff B, Saalabian AA, Hahne M, van Schoonhoven J, Prommersberger KJ. Neuropathie des N. medianus nach perilunären Luxationsverletzungen [Median nerve neuropathy after perilunate dislocation injuries]. Handchir Mikrochir Plast Chir. 2014;46:1638.

23. Imao K, Tsubokawa N, Maki Y. Trans-scaphoid-perilunate dislocation with an ulnar nerve injury. J Hand Surg Eur Vol. 2016;41:111-2. 